\title{
Estereotipos científicos: percepción del alumnado de un centro de adultos de Granada (España)
}

\section{Science stereotypes: perception of the students of an adult center in Granada (Spain) \\ Estereótipos científicos: percepção dos alunos de um Centro para Adultos em Granada (Espanha)}

\author{
Cayetana Serna-Rosell ${ }^{1}$ \\ José Miguel Vílchez-González²
}

Recibido: diciembre de 2017

Aceptado: abril de 2018

Para citar este artículo: Serna-Rosell, C., y Vílchez-González, J. M. (2018). Estereotipos científicos: percepción del alumnado de un Centro de Adultos de Granada (España). Revista Científica, 32(2), 169-182. Doi: https://doi. org/10.14483/23448350.12799

\section{Resumen}

Numerosas investigaciones han demostrado que la percepción social de la ciencia está impregnada de visiones ingenuas y estereotipos transmitidos por la sociedad. Pese a que existen numerosos trabajos sobre este campo, la mayoría de estudios que respaldan la existencia de estereotipos científicos se han hecho en niños y adolescentes y en su mayoría fueron realizados en otros países. Este trabajo pretende reflejar cuál es la imagen de científico en un grupo de personas adultas residentes en Granada, España, a través del análisis de 88 dibujos utilizando la estrategia "Draw a scientist test" (DAST). Como novedad, se incluye un estudio piloto con el objetivo de comprobar si es posible cambiar este estereotipo científico mediante uso de fotografías. Los resultados evidencian una imagen estereotipada de comunidad científica, que se muestra de forma similar en personas de diferentes edades, sexo, procedencia o nivel intelectual. Además, esta imagen es resistente al cambio.
Palabras clave: estereotipos científicos, naturaleza de la ciencia, percepción social de la ciencia, test dibuja un científico.

\begin{abstract}
Numerous studies have shown that social perception of Science is infused with naive visions and society transmitted stereotypes. Despite the large amount of research existing on this field, most of the studies that support the existence of Science stereotypes were carried out on children and youngsters and the majority of same took place in other countries. The present work aims to reflect the social perception of Science within a group of adult people residing in Granada, Spain, and this through the analysis of 88 drawings using the "Draw a scientist test" method. As a novelty, this work includes a pilot study with the purpose to get to know if it would be possible to change this Science stereotypic perception by using pictures. The results show a certain stereotyped image of the scientist, which is similarly shown in
\end{abstract}


people of different ages, sex, origin or intellectual level. In addition, this image is resistant to change.

Keywords: draw-a-scientist test, nature of science social, perception of science, stereotypic images of scientists.

\section{Resumo}

Numerosas investigações têm mostrado que a percepção social da ciência está impregnada de visões ingênuas e estereótipos transmitidos pela sociedade. Embora já existam inúmeros trabalhos sobre este campo, a maioria de estudos que apoiam a existência de estereótipos científicos foram realizados em crianças e adolescentes e na sua maioria foram levados a cabo em outros países. Este trabalho pretende refletir qual é a imagem de cientista num grupo de pessoas adultas residentes em Granada, Espanha, através da análise de 88 desenhos utilizando a estratégia "Draw a scientist test". Como novidade, inclui-se um estudo-piloto com o objetivo de comprovar se é possível mudar este estereótipo científico mediante o uso de fotografias. Os resultados evidenciam uma imagem estereotipada da comunidade científica que se mostra de forma similar em pessoas de diferentes idades, sexo, procedência ou nível intelectual. Além disso, esta imagem é resistente à mudança.

Palavras-chaves: estereótipos científicos, natureza da ciência, percepção social da ciência, teste desenha um cientista.

\section{Introducción}

La influencia que los mensajes en formato imagen tienen sobre la sociedad actual es innegable, y los medios de comunicación se sirven de ella como principal medio para llegar a las masas. La educación no es ajena a este fenómeno; por eso, algunas investigaciones argumentan a favor del uso de la imagen como una eficaz herramienta para la enseñanza y el aprendizaje escolar (Perales, Vílchez y Sierra, 2004). En Didáctica de las Ciencias la imagen es muy utilizada como recurso de enseñanza y aprendizaje de los contenidos de ciencia y sobre ciencia. Sin embargo, ¿qué ocurre cuando las imágenes que percibimos no son del todo adecuadas? Este trabajo pretende realizar un análisis sobre la percepción de la comunidad científica del alumnado de un centro de adultos de Granada (España). Emplea la metodología "Draw-a-scientist-test" (DAST), una sencilla prueba propuesta por Chambers (1983) que consiste en realizar un dibujo de un científico a través del cual se hace aflorar la imagen que de la misma tienen estos alumnos.

Como complemento a la prueba anterior, se ha realizado un estudio piloto para comprobar si es posible modificar los estereotipos científicos a través del uso de imágenes.

\section{Marco teórico}

Las evaluaciones comparativas internacionales son uno de los instrumentos más empleados en la actualidad para detectar las fortalezas y debilidades de los sistemas educativos. Por ejemplo: las pruebas del Programme for International Student Assessment (PISA), elaboradas e implementadas en todos los países miembros de la Organización para la Cooperación y el Desarrollo Económicos (OCDE), en las que se evalúa a estudiantes de dichos países con el fin de comprobar el rendimiento académico y orientar a las administraciones educativas en el desarrollo del currículo escolar. En el marco teórico de las últimas pruebas PISA centradas en ciencias y realizadas en 2015, se menciona que la ciencia es algo omnipresente en nuestras vidas que la ciencia no se limita a tubos de ensayo y tablas periódicas, es algo que va más allá, puesto que representa las bases de prácticamente todas las herramientas que usamos. Añaden y que no es solo un campo para los científicos, debido a que todo el mundo necesita ser capaz de pensar como un científico para valorar datos y llegar a conclusiones útiles y para entender que la verdad científica puede ir cambiando con el tiempo conforme se realizan nuevos descubrimientos y los humanos desarrollamos una mayor comprensión de las leyes naturales y de las posibilidades y los límites de la tecnología (OCDE, 2016). 
PISA 2015 habla de crear cultura científica y ciudadanos competentes, lo que exige no solo conocer los contenidos de ciencias sino que también requiere comprender cómo se genera y evoluciona el conocimiento científico y el grado de fiabilidad con el que se lleva a cabo. Esto es lo que algunos autores han argumentado a favor de enseñar naturaleza de la ciencia (NDC) (Lederman, 2006).

Cada vez es mayor el acuerdo sobre la inclusión de una enseñanza de la $\mathrm{NdC}$ en el currículo de ciencias como "elemento innovador de la alfabetización científica y tecnológica para todas las personas" (Acevedo-Díaz, Vázquez, Manassero y AcevedoRomero, 2007, p. 203). No obstante, tal como apuntan Fernández, Gil, Carrascosa, Cachapuz y Praia (2002), existen numerosas investigaciones que muestran que la enseñanza de las ciencias a cualquier nivel apenas proporciona ocasión a los estudiantes de familiarizarse con las características de la labor científica, y "como consecuencia de ello las concepciones de los estudiantes, e incluso de los mismos profesores, de la naturaleza de la ciencia no difieren de la visiones ingenuas adquiridas por impregnación social" (Fernández et al., 2002, p. 477). Estos autores defienden que uno de los principales obstáculos para la renovación de la enseñanza de las ciencias es, precisamente, la importancia de estas visiones deformadas. Es decir, cualquier intento de representar una imagen de la ciencia, sea cual sea, siempre va a estar limitado o fragmentado (Acevedo et al., 2007). La imagen que de la ciencia y los científicos tiene la sociedad no está, por supuesto, exenta de estas visiones deformadas o ingenuas. Así, tal como sugiere Sanmartí (2002), cualquier persona tiene también su propia visión sobre la ciencia y los científicos, fruto tanto de la enseñanza recibida como de vivir en un contexto social en el que priman concepciones de la ciencia muy estereotipadas.

Son numerosos los estudios realizados durante el último medio siglo sobre la percepción social de la ciencia, y en todos ellos se destaca que existe una visión muy sesgada de la ciencia y de la labor científica. En muchas ocasiones se percibe como individualista y elitista, objetiva, neutra, infalible, ahistórica, etc., tal y como indican Fernández et al. (2002) en su revisión sobre las visiones deformadas de la ciencia transmitidas por la enseñanza.

La ciencia, en general, se concibe como "la verdad", que en muchas ocasiones es peligrosa, y el científico como alguien importante que realiza una labor significativa. Durante las décadas de los 30 y los 40 del siglo pasado, los científicos que aparecían en televisión eran hombres blancos, de edad avanzada, que estaban locos o eran malvados. Poco a poco esta imagen fue cambiando, mostrando una élite de hombres y mujeres, principalmente de raza blanca, obsesionados con su trabajo, mayores, sin familia y, en muchas, ocasiones peligrosos y dirigidos por el fracaso (Schibeci, 1986; Whitle, 1997).

También es frecuente que se presenten como hombres calvos o de pelo cano, con gafas de mucho aumento, despistados y con el único propósito en su vida que el de aportar los resultados de su trabajo a ese campo de conocimientos acumulados que forman la ciencia. La ciencia se asemeja, comúnmente, a una especie de química aplicada realizada en el laboratorio (Vázquez y Manassero, 1998).

El primer estudio sobre estas cuestiones fue realizado por Mead y Métraux (1957). En su estudio piloto Ilamado Image of the Scientist among High-School Students indagaron acerca de la percepción que los alumnos de instituto tenían acerca de la ciencia y los científicos, e intentaron describir sistemáticamente esta imagen estereotipada. Los resultados mostraron que los estudiantes, generalmente, definen a los científicos a través de estereotipos, como se muestra en la siguiente declaración de los investigadores:

El científico es un hombre que lleva una bata blanca y trabaja en un laboratorio. Es mayor o de mediana edad y lleva gafas... puede tener barba... 
Está rodeado por instrumentos: tubos de ensayo, mecheros Bunsen, frascos y botes...una jungla de instrumentos de vidrio y máquinas extrañas. Escribe cuidadosamente en cuadernos... Un día puede levantarse y gritar: “¡Eureka! ¡Lo he encontrado!”... A través de su trabajo, la gente obtiene nuevos y mejores productos... su trabajo puede ser peligroso... Siempre está leyendo. (Mead y Métraux, 1957, citado por Chambers, 1983, p. 256).

En un estudio posterior realizado por Chambers (1983), en el que analizó 4807 dibujos realizados por niños y adolescentes, categorizó una serie de elementos comunes que se repetían y que respondían a la descripción estereotipada del científico. Estudios posteriores, centrados en el análisis de elementos culturales como la literatura, cine, televisión o publicidad y su posible influencia sobre la imagen estereotipada de los científicos y de la ciencia, arrojaron como resultado "la existencia de estereotipos científicos en los elementos analizados" (Vázquez y Manassero, 1998, p. 4).

Puesto que la mayoría de estudios y revisiones acerca de la percepción de la imagen de los científicos llevados a cabo en los últimos años se han centrado en niños y adolescentes (Kahle, 1989; Barman, 1997; Sjøberg, 2000; Finson, 2002), nos planteamos como objetivo de este trabajo examinar los estereotipos de científicos en personas adultas y comprobar si difieren de los resultados de estudios anteriores, ya que, como parece suceder, estas percepciones están arraigadas socialmente y constituyen uno de los obstáculos que dificultan el aprendizaje de la ciencia (Sanmartí, 2002). Con la finalidad de responder a este objetivo se analizan las imágenes de científicos dibujadas por un grupo de alumnos de un centro de adultos de Granada (España) para intentar encontrar respuesta a las siguientes cuestiones:

1. ¿Qué imagen de la comunidad científica tiene el alumnado de un centro de adultos de Granada?
2. ¿Es posible cambiar la percepción del estereotipo científico a través de una intervención basada en el uso de imágenes no estereotipadas?

\section{Metodología}

Para responder a los interrogantes de investigación se ha procedido, en primer lugar, a identificar la imagen de científico del alumnado a través de la aplicación del DAST; en segundo lugar, se pretendió provocar un conflicto cognitivo a través del uso de imágenes no estereotipadas de científicos (pretest). Finalmente se presentaron nuevas imágenes (postest) para comprobar si las ideas previas habían sufrido algún cambio tras la intervención.

\section{Participantes y contexto}

La población objeto de estudio es el alumnado de un centro de educación permanente de Granada (España), de nivel socioeconómico medio. En total han participado 88 estudiantes de diferentes edades, entre 18 y 85 ; nacionalidades, 74 españoles y 12 extranjeros; sexo,28 hombres y 58 mujeres; y niveles educativos, sin estudios hasta titulados universitarios). Podría decirse, pues, que se ha contado con una muestra heterogénea y representativa de la sociedad (figura 1).

Por su parte, para el estudio piloto acerca de si es posible cambiar la percepción del estereotipo científico a través del uso de imágenes de científicos se seleccionaron, por su capacidad de argumentación, dos de los grupos-clase (G1 y G2, en adelante), con un total de 26 estudiantes. En el grupo G1 el número de participantes fue de 14 en la primera sesión y 10 en la segunda; en el G2, 12 en la primera y16 en la segunda.

\section{Instrumentos}

Para la primera parte de la actividad (DAST) se pidió al alumnado que realizaran un dibujo de personas que dedican su actividad profesional a 


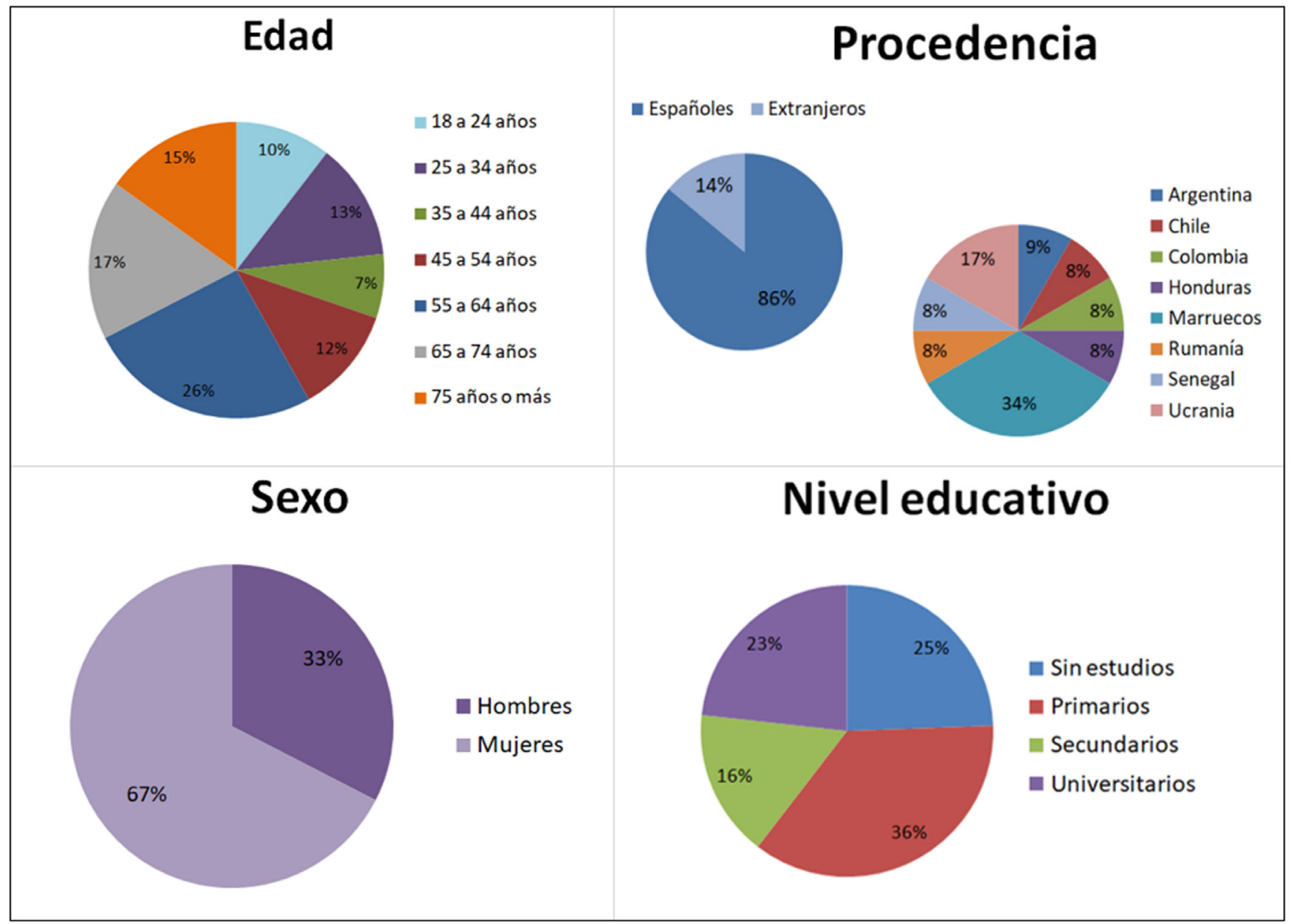

Figura 1. Distribución del alumnado por edad, procedencia, sexo y nivel.

Fuente: elaboración propia del autor.

la ciencia, y argumentaran por qué lo habían dibujado de ese modo. A fin de obtener datos contextuales se recogieron datos sobre la edad, sexo, nacionalidad y nivel de estudios.

Otra cuestión que se quería estudiar es si los medios de comunicación habían influido en su visión sobre la ciencia, y para ello se añadió a la plantilla proporcionada una serie de ítems en relación a si solían consultar noticias sobre ciencia y, en caso afirmativo, cuál era su principal fuente de consulta.

En la segunda parte de la actividad, tanto en el pretest como en el postest, se mostró a los participantes una serie de parejas de imágenes de personas, una de ellas científica y la otra no, y se les pidió que identificaran al científico o científica en cada par. En ambos momentos el alumnado debía explicar los motivos de sus elecciones. Al final del cuestionario del postest se incluyó la pregunta "¿qué has aprendido a través de esta actividad?", a fin de comprobar si había habido algún cambio en la percepción de los estudiantes con respecto al pretest.

\section{Procedimiento}

Todo el proceso se desarrolló sin previo aviso a los alumnos para que el resultado no se viera influenciado por una posible preparación previa. El procedimiento seguido fue el siguiente: 


\section{Primera parte: dibuja a un científico (DAST)}

Para identificar la percepción del alumnado acerca de la comunidad científica se pidió a los estudiantes que realizaran un dibujo que representara a la gente que trabaja en ciencia y explicaran con detalle por qué habían realizado así sus dibujos. Para la realización de la actividad se les dio treinta minutos y advirtiéndoles que no podían consultar ninguna imagen en sus dispositivos móviles. Los dibujos realizados por los alumnos fueron registrados con números consecutivos, según se iban recogiendo para su posterior localización.

\section{Segunda parte: estereotipos científicos a través de imágenes. Estudio piloto}

El estudio piloto, segunda parte de la actividad, se llevó a cabo en dos fases. En la primera (pretest), se mostró a los dos grupos de estudiantes seleccionados una serie de quince pares de imágenes, y se les pidió que identificaran en cada par al científico o científica. El procedimiento seguido fue el siguiente:

1. Se le explicó al grupo que se les iba a mostrar quince pares de imágenes, en donde aparecían dos personas identificadas como A y B. En cada par había una persona que era científica y otra que no lo era. A continuación, se les pasó una plantilla en la que debían seleccionar, para cada par de imágenes, la persona que, a su juicio, era científica.

2. Repartidas las plantillas, se mostró cada par de fotos durante el tiempo suficiente para que pudiesen fijarse en aquellos detalles de las imágenes que motivaron su elección (indumentaria, rasgos faciales, entorno, etc.).

3. Comenzó una fase de discusión en grupo. Se volvieron a mostrar los pares de imágenes y se pidió a los alumnos que justificaran su elección, dejando que discutieran entre sí los motivos sin desvelarse si habían acertado o no. La discusión de grupo fue grabada en audio y parcialmente transcrita.
4. Terminada la discusión, se mostraron de nuevo las imágenes, para descubrir, ahora sí, quién era el científico o científica en cada par, y aportar algunos datos sobre sus trabajos.

Tras dejar pasar unos días (14 días para G1 y 16 para G2), tuvo lugar la segunda fase del estudio piloto (postest), en la que se mostró a los dos grupos de estudiantes otra serie de quince pares de imágenes para que identificasen, en cada par, la del científico o científica, pero en esta ocasión también se les pidió la razón de su elección. En esta ocasión tardaron más, en general, en rellenar el cuestionario y aunque aquí no se abrió debate, se empleó el mismo tiempo que para el pretest, 45 minutos con cada uno de los grupos.

Tanto para el pretest como para el postest, la búsqueda de imágenes se hizo a través de la sección "Imágenes" del buscador Google, mediante los siguientes términos de búsqueda: "estereotipo científico", "mujeres y ciencia" y "científicos importantes actuales". Para las personas no científicas se introdujeron los términos: "modelos que hacen de científicos", "personas con bata de laboratorio" y "mujeres escritoras".

La selección de imágenes se hizo respondiendo a cuatro categorías:

1. Imágenes de científicos que se acercan al estereotipo científico, hombres mayores o de mediana edad, calvos o despeinados, personas con bata de laboratorio, junto a instrumentos de vidrio o pizarras con fórmulas, etc.

2. Imágenes no estereotipadas de científicos, sin bata de laboratorio, sin gafas, sonrientes, personas negras, jóvenes, mujeres, etc.

3. Imágenes de personas que, sin ser científicas, se acercan al estereotipo científico,personas con pinta de "científico loco", serias, con gafas, etc.

4. Imágenes de personas no científicas que no responden a la imagen de estereotipo científico, sin batas ni ropa de trabajo relacionada con la ciencia, sin objetos relacionados con ciencia, mujeres jóvenes, etc. 
Para cada categoría se seleccionaron 15 imágenes y después se combinaron buscando parejas que condujesen al observador a posible engaño (figura 2).

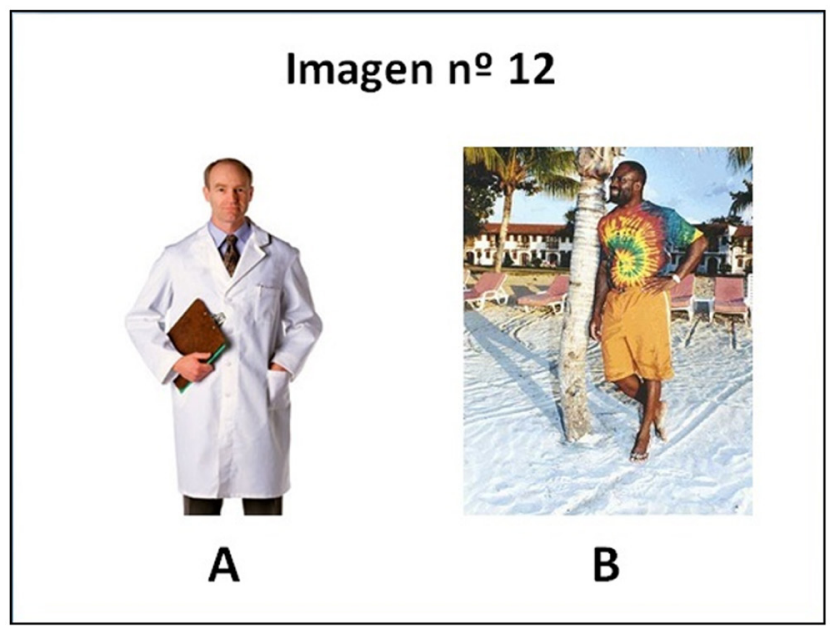

Figura 2. Ejemplo de imagen estereotipada y no estereotipada de científico, A es un actor y B, el científico nigeriano Philip Emeagwali.

Fuente: elaboración propia de los autores.

\section{Discusión de resultados}

\section{Primera parte: dibuja a un científico (DAST)}

Del total de dibujos realizados por el alumnado (88), dos fueron desechados por no responder a lo que se pedía (en uno de ellos se representaba un pupitre y en el otro un cuadro de "La Mona Lisa"). Se han tenido en cuenta, pues, los 86 dibujos restantes.

Para el análisis de dibujos se han tomado como referencia los indicadores empleados en estudios anteriormente hechos por varios autores (Chambers, 1983; Vázquez y Manassero, 1998) y se han modificado para contar con más indicadores de imagen estereotipada del científico. Finalmente se han tenido en cuenta los siguientes:

1. Persona solitaria.

2. Hombre mayor o de mediana edad.

3. Bata de laboratorio (no necesariamente blanca).

4. Con gafas.
5. Calvo o despeinado.

6. Con pelo facial.

7. Rodeado de objetos o símbolos de investigación (material de vidrio, microscopios, libros, símbolo del átomo, etc.).

Al igual que ocurrió en estudios anteriores (Vázquez y Manassero, 1998; Ruiz-Mallén y Escalas, 2012) el análisis de los dibujos revela que la gran mayoría representan a una sola persona (73 casos, el $84.9 \%$ ), mientras que el resto contienen a más de una (ocho casos) o no incluyen a ninguna (cinco casos). En los que se representa a más de una, la casi totalidad representan dos (seis casos) y solo unos pocos dibujan a cuatro (un caso) o seis (un caso). El hecho de representar a una sola persona se puede interpretar como indicador de una visión individualista y elitista de la ciencia (Fernández et al., 2002).

En cuanto al sexo de las personas dibujadas, la mayoría de alumnos representan a hombres (64 casos, frente a los seis de mujeres), aunque aparecen algunos casos en los que el sexo es indefinido (seis casos) o aparecen ambos sexos en el mismo dibujo (cinco casos). Los dibujos en los que aparecen mujeres científicas, ya sea solas o junto a un hombre, han sido hechos en su mayoría por mujeres. Solo hay dos casos de mujeres científicas dibujadas por un hombre.

Respecto a la edad del científico, predominan los dibujos que representan a personas mayores o de mediana edad frente a los que representan jóvenes (48 casos frente a ocho), lo cual se corresponde con el estereotipo más general de la ciencia (Jiménez y Álvarez, 1992, citado por Vázquez y Manassero, 1998). En los 25 casos restantes no se disponía de suficientes datos para identificar la edad del científico dibujado.

En lo que respecta a la indumentaria, abundan los dibujos en los que los científicos visten una bata de laboratorio, por lo que este indicador sigue siendo mayoritario. La presencia de gafas está también bastante extendida aunque no es mayoritaria, ya que solo aparecen en un $40 \%$ de los dibujos (32 casos). 
Otros elementos indicadores de la imagen estandarizada de científico son la presencia de pelo facial y el hecho de que el científico suele representarse como una persona calva o despeinada. Solo en 22 casos el científico ha sido representado con pelo facial, predominando la barba (13 casos) sobre el bigote (seis casos), o ambos (tres casos), lo que supone que un $70 \%$ del alumnado ha representado imágenes de científicos sin pelo facial. Esto coincide con los resultados de Vázquez y Manassero (1998), pues "la presencia de pelo facial, en cualquiera de sus formas, no es ni siquiera mayoritaria entre los dibujos que representan hombres, de modo que el estereotipo de la barba, dominante en los estudios iniciales, parece un poco relegado actualmente" (p.20). En cuanto al segundo de estos indicadores (persona calva o despeinada), coincidiendo con los resultados de estudios anteriores (Boylan, Hill, Wallace y Wheeler, 1992), el 79\% de los dibujos representan a científicos calvos (19 casos) o despeinados (45 casos), indicativo de que este elemento sigue estando bastante arraigado en el estereotipo científico de los estudiantes.

A modo de resumen, la figura 3 muestra los elementos que aparecen con mayor frecuencia en los dibujos realizados, que corresponden a la imagen estandarizada de científico.

El último de los indicadores analizados hace referencia a la presencia en los dibujos de objetos relacionados con la ciencia. En 75 dibujos (87.2\%) el científico aparece rodeado de algún tipo de objeto científico, muchas veces más de uno (tabla 1). Cuando en un mismo dibujo aparece más de un objeto de la misma clase, como suele pasar con el material de vidrio, se ha contabilizado como un solo objeto. Se han identificado un total de 110 objetos científicos. Entre estos, los que aparecen con mayor frecuencia son material de vidrio (39 casos), libros (ocho casos), y planetas/Sol (ocho casos). Los aparatos de observación, como microscopios y telescopios, aparecen en menor medida (cuatro y un casos, respectivamente). También aparecen algunos objetos científicos como un acelerador de partículas (contado como tecnología) o

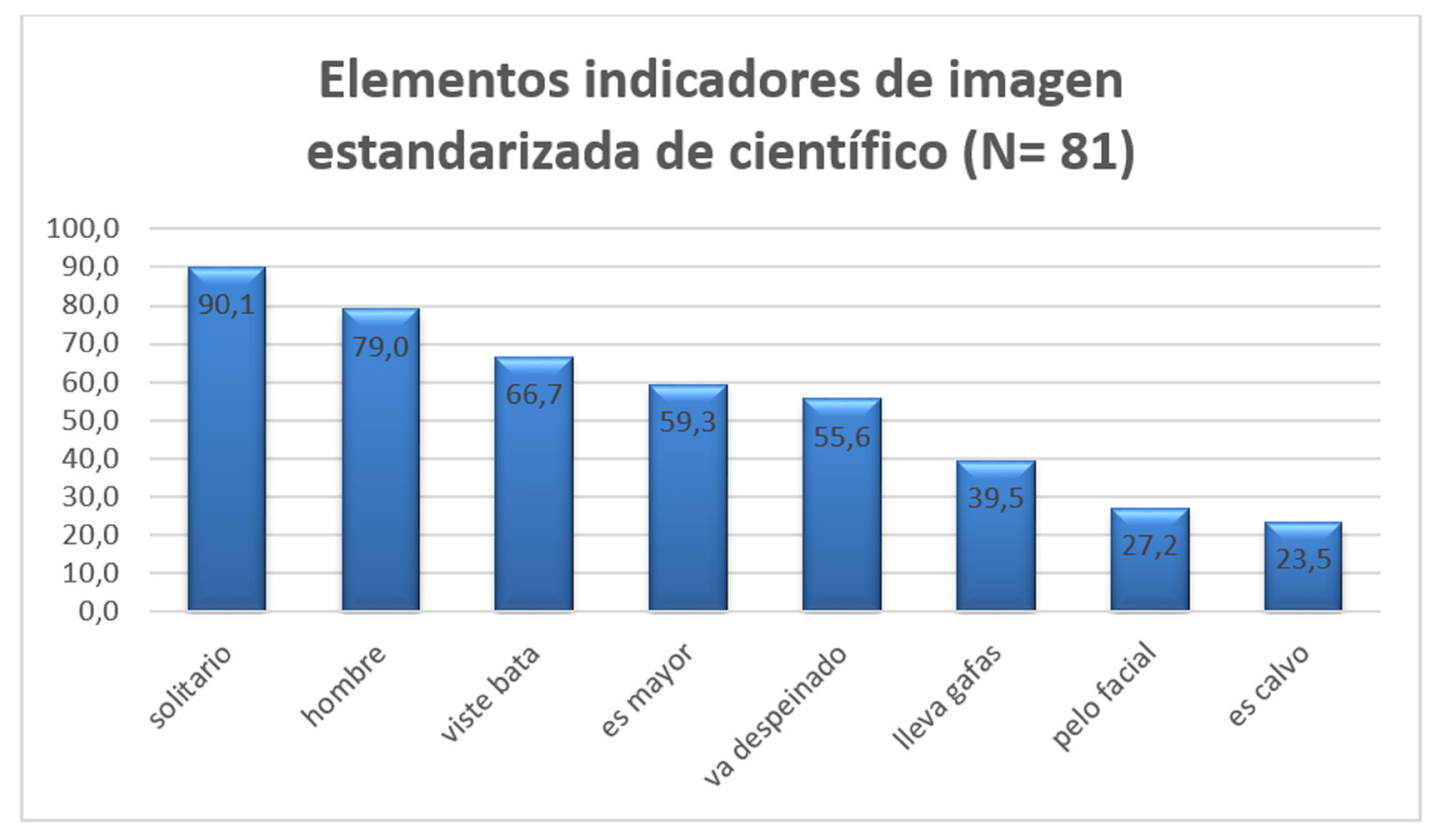

Figura 3. Porcentaje de los elementos del científico representados en los dibujos, $n=81$.

Fuente: elaboración propia del autor. 
unas placas solares. Solo en 11 casos $(12.8 \%)$ el científico dibujado no aparece junto a ningún tipo de objeto.

Para los objetos más frecuentes, las mujeres dibujan más material de vidrio y libros, mientras que los hombres dibujan más material de vidrio, planetas/Sol y átomos.

Otra cuestión a destacar, en algunos dibujos se han representado a uno o más personajes famosos, con mayor representación masculina que femenina (18 frente a cinco casos). Entre los hombres encontramos alusiones a Einstein (siete casos), Stephen Hawking, Nikola Tesla, Neil Armstrong y Galileo Galilei (dos casos de cada uno) o Isaac Newton, Pedro Duque e Ibn Sina (un caso cada uno); entre las científicas, solo Marie Curie aparece representada en dos ocasiones. Algunos alumnos también han representado a personajes de ficción de series de televisión y cómics, lo que, sumado a que en sus explicaciones muchos hacen referencia a lo que han visto en series de televisión o noticias, apoyan lo que algunos autores ya escribieron acerca de la influencia de los medios de comunicación a la hora de conformar y mantener las ideas preconcebidas sobre ciencias (Vílchez-González y Perales-Palacios, 2006).

EI DAST como metodología de análisis puede no aportar suficientes datos por sí misma, y por ello se les pidió que además de realizar el dibujo explicasen por qué lo habían realizado así. En la mayoría de los casos no han respondido adecuadamente a esta petición, por lo que no es posible conocer más detalles que los que aportan los propios dibujos. En los que sí lo han hecho, las

Tabla 1. Objetos científicos identificados en los dibujos ( $N=110)$.

\begin{tabular}{|c|c|c|c|c|c|c|}
\hline \multirow{2}{*}{ Objeto científico } & \multirow{2}{*}{ Casos } & \multirow{2}{*}{ Total $(\%)$} & \multicolumn{2}{|c|}{ Dibujados por hombres } & \multicolumn{2}{|c|}{ Dibujados por mujeres } \\
\hline & & & Casos & $\%$ & Casos & $\%$ \\
\hline Material vidrio & 39 & 35,5 & 8 & 7,3 & 31 & 28,2 \\
\hline Libros (incluye notas) & 8 & 7,3 & 2 & 1,8 & 6 & 5,5 \\
\hline Planetas/Sol & 8 & 7,3 & 5 & 4,5 & 3 & 2,7 \\
\hline Ordenador & 7 & 6,4 & 2 & 1,8 & 5 & 4,5 \\
\hline Átomo & 6 & 5,5 & 4 & 3,6 & 2 & 1,8 \\
\hline Bombilla & 6 & 5,5 & 1 & 0,9 & 5 & 4,5 \\
\hline Nave espacial & 5 & 4,5 & 2 & 1,8 & 3 & 2,7 \\
\hline Tecnología & 5 & 4,5 & 2 & 1,8 & 3 & 2,7 \\
\hline Microscopio & 4 & 3,6 & 2 & 1,8 & 2 & 1,8 \\
\hline ADN & 4 & 3,6 & 1 & 0,9 & 3 & 2,7 \\
\hline Hospital & 3 & 2,7 & 1 & 0,9 & 2 & 1,8 \\
\hline Pizarra & 3 & 2,7 & 0 & 0,0 & 3 & 2,7 \\
\hline Animales & 3 & 2,7 & 1 & 0,9 & 2 & 1,8 \\
\hline Placa solar & 2 & 1,8 & 1 & 0,9 & 1 & 0,9 \\
\hline Telescopio & 1 & 0,9 & 0 & 0,0 & 1 & 0,9 \\
\hline Tabla periódica & 1 & 0,9 & 0 & 0,0 & 1 & 0,9 \\
\hline Bomba & 1 & 0,9 & 0 & 0,0 & 1 & 0,9 \\
\hline Polea & 1 & 0,9 & 0 & 0,0 & 1 & 0,9 \\
\hline Pieza de nave & 1 & 0,9 & 0 & 0,0 & 1 & 0,9 \\
\hline Lupa & 1 & 0,9 & 0 & 0,0 & 1 & 0,9 \\
\hline Célula & 1 & 0,9 & 0 & 0,0 & 1 & 0,9 \\
\hline Total objetos & 110 & 100,0 & 32 & 29,1 & 78 & 70,9 \\
\hline
\end{tabular}

Fuente: elaboración propia de los autores. 
respuestas, aunque muy escuetas, pueden servir para agrupar a los científicos, según sus explicaciones, como persona que:

1. Inventa o fabrica algo, fórmulas, bomba, pesticidas, piezas para naves espaciales o aparatos de radio, etc.

2. Investiga la cura de enfermedades, cáncer, alzhéimer.

3. Relaciona con cosas que ha visto en la televisión.

4. Descubre cosas (gravedad, relatividad, planetas).

\section{Segunda parte: estereotipos científicos a través de imágenes. Estudio piloto}

Para el análisis de las respuestas obtenidas en el estudio piloto se han registrado los aciertos y fallos, por grupos. Las frecuencias de aciertos de ambos grupos en el pretest y el postest se presentan en la figura 4.

Aunque podría esperarse que el número de aciertos de los alumnos aumentara tras la intervención, ocurre lo contrario. En ambos grupos el porcentaje de aciertos disminuye de forma sustancial, por lo que ahora la cuestión que se plantea es cuáles pueden ser los motivos de que esto ocurra.

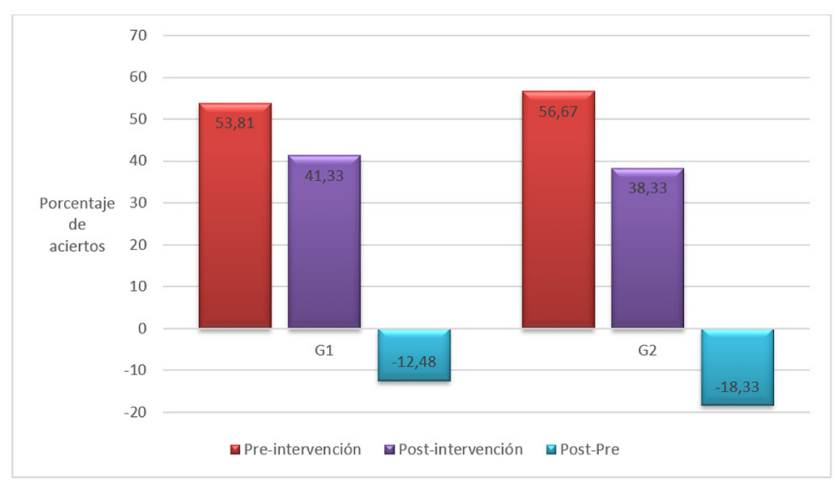

Figura 4. Porcentaje de aciertos en pretest y postest.

Fuente: elaboración propia de los autores.

Por su parte, los datos aportados por el alumnado acerca de sus hábitos de consulta de medios de comunicación (figura 5) revelan que algo más de la mitad, el $54.7 \%$ (47 casos), declara que suele consultar noticias relacionadas con la ciencia, utilizando mayoritariamente la televisión (39.5\%) como primera fuente de consulta, seguida por Internet $(27.9 \%)$, prensa $(19.8 \%)$ y radio $(18.8 \%)$. Estas podrían ser, pues, las fuentes que participan en la difusión de las imágenes estereotipadas de la comunidad científica.

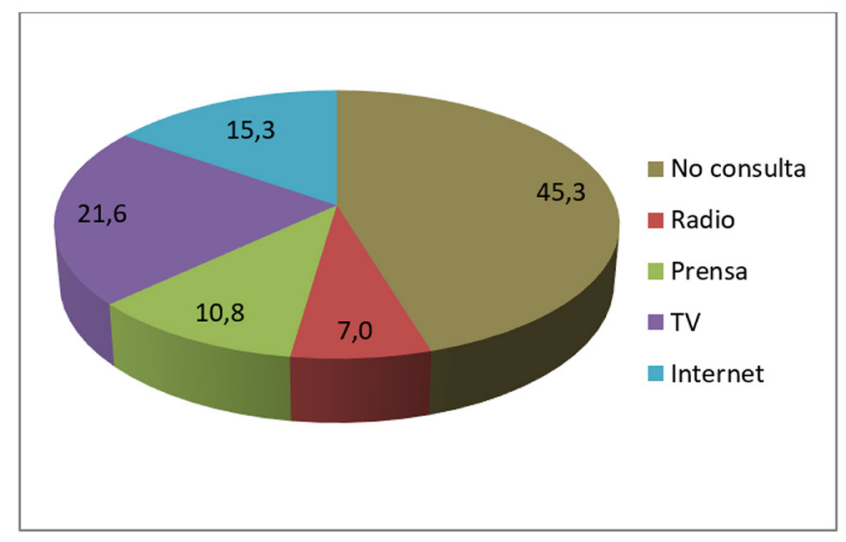

Figura 5. Porcentaje de alumnado que consulta noticias sobre ciencia, y fuentes de consulta.

Fuente: elaboración propia de los autores.

\section{Razones expuestas por los alumnos}

En la tabla 2 se recogen los motivos de elección expuestos por los alumnos en el pretest y en el postest.

La percepción del alumnado antes y después de la intervención es muy similar. En ambos casos la mayoría de alumnos basan su elección en, principalmente, el estereotipo científico (elección de hombre frente a mujer, viejo frente a joven, con bata de laboratorio u pizarras con fórmulas frente a personas que no aparecían con esta indumentaria u objetos, etc.).

Aunque los motivos de elección son prácticamente iguales antes y después, en el postest aparece un nuevo motivo que llama la atención por alejarse del estereotipo científico. Un alumno manifiesta haber elegido al científico porque su expresión "manifiesta incertidumbre", hecho que combate la visión rígida e infalible de la ciencia 
Tabla 2. Motivos que dan los alumnos en su selección de científicos.

\begin{tabular}{ll}
\hline \multicolumn{1}{c}{ Razones pretest } & \multicolumn{1}{c}{ Razones postest } \\
\hline $\begin{array}{l}\text { Aspecto desaliñado/ "científico loco" } \\
\text { Gafas: vista cansada de estudiar, leer... }\end{array}$ & $\begin{array}{l}\text { Aspecto desaliñado/ "científico loco" } \\
\text { Pelo calvo o despeinado }\end{array}$ \\
$\begin{array}{l}\text { Pelo facial } \\
\text { Pelo calvo o despeinado }\end{array}$ \\
$\begin{array}{l}\text { Indumentaria (sobre todo si lleva bata) } \\
\text { Edad }\end{array}$ & Pelo facial \\
Sexo & Edumentaria (sobre todo si lleva bata) \\
Raza, color de piel & Sexo \\
No sonríe: parece serio, enfadado o infeliz & Raza, color de piel \\
Expresión: inteligente ambicioso, seguro & No sonríe: parece serio, enfadado o infeliz \\
Ordenado/desordenado & Expresión: inteligente ambicioso, seguro \\
Aparece con libros o cuadernos & Aparece con libros o cuadernos \\
Pizarra con fórmulas & Pizarra con fórmulas \\
Lugar donde se encuentra & Lugar donde se encuentra \\
Comportamiento & Comportamiento: observa detalles \\
& Manifiesta incertidumbre \\
\hline
\end{tabular}

Fuente: elaboración propia de los autores.

(Fernández et al., 2002) al ver al científico como una persona que tiene dudas, que reformula, y no una persona fría y cuadriculada, como muchas veces se piensa.

También llama la atención que, si bien es cierto que los resultados obtenidos en el postest muestran que los alumnos siguen fallando a la hora de seleccionar la imagen del científico, incluso más que en el pretest, aparecen indicios que pueden sugerir que el alumnado ha sufrido un conflicto cognitivo, puesto que:

1. Aparecen alumnos que dejan sin responder algunas casillas del cuestionario (dos casos en pretest frente a seis en postest).

2. Aumenta de forma considerable el número de elecciones cuya explicación es "no lo sé" o bien el alumno elige una de las opciones pero explica no saber quién es el científico porque "podría ser cualquiera de los dos".

Por último, ante la pregunta “¿Qué has aprendido a través de esta actividad?" surgen respuestas que hablan de los estereotipos científicos. La mayoría de participantes acepta que se ha dejado llevar, en ambas fases, por los estereotipos de científico, aunque a la vez explican que:

"cualquier persona puede ser científico, aunque no lleven bata blanca o estén en un laboratorio"

O que "un científico no siempre tiene que ser hombre o una persona de más edad...".

Lo que nos lleva a preguntarnos por qué si los alumnos reflexionan sobre esto, se dejan arrastrar por la imagen estereotipada de la comunidad científica. Tal como ya apuntaba Sanmartí (2002), las ideas previas actúan como obstáculos, pues se encuentran muy arraigadas en el alumnado.

\section{Conclusiones}

A pesar del gran desarrollo que la ciencia y la tecnología han experimentado en las últimas décadas, parece que la percepción social sobre la comunidad científica apenas ha variado desde los estudios pioneros realizados por Mead y Métraux.

Las conclusiones de Chambers respecto a que las pruebas DAST reflejan representaciones sociales basadas en imágenes estereotípicas del científico relacionadas con un hombre de mediana edad, que lleva bata blanca y gafas, suele ser calvo o ir 
despeinado y cuya acción principal es la experimentación o invención en un laboratorio con instrumentos como probetas o tubos de ensayo, que a menudo echan humo, siguen siendo, aunque con pequeñas variaciones, igual de válidas hoy en día y se muestran del mismo modo en personas de diferentes edades, sexo, procedencia o nivel intelectual, por lo que parece existir un fuerte arraigo social. Un ejemplo de ello es la figura 6, que muestra dos dibujos de similares características hechos por dos alumnas de edades muy diferentes.

Difícilmente estas concepciones pueden ser modificadas por medio de una intervención puntual, pues las ideas previas acaban regresando con el tiempo, siendo algunas de las causas de ello la influencia del lenguaje y de los diferentes medios de comunicación, además de la existencia de errores conceptuales en los libros de texto y los materiales didácticos (Carrascosa Alís, 2013). La literatura y los medios de comunicación, tan importantes en la sociedad del conocimiento en que nos hallamos inmersos, ayudan a conformar y mantener estos estereotipos y suponen un obstáculo difícilmente superable, aunque también podrían constituir una eficaz herramienta de trabajo para luchar contra estas visiones deformadas.

\section{Líneas futuras de investigación y propuestas de mejora}

Para poder asegurar la posibilidad de cambiar la percepción del estereotipo científico a través del uso de imágenes debería realizarse una intervención más prolongada en el tiempo y con mayor
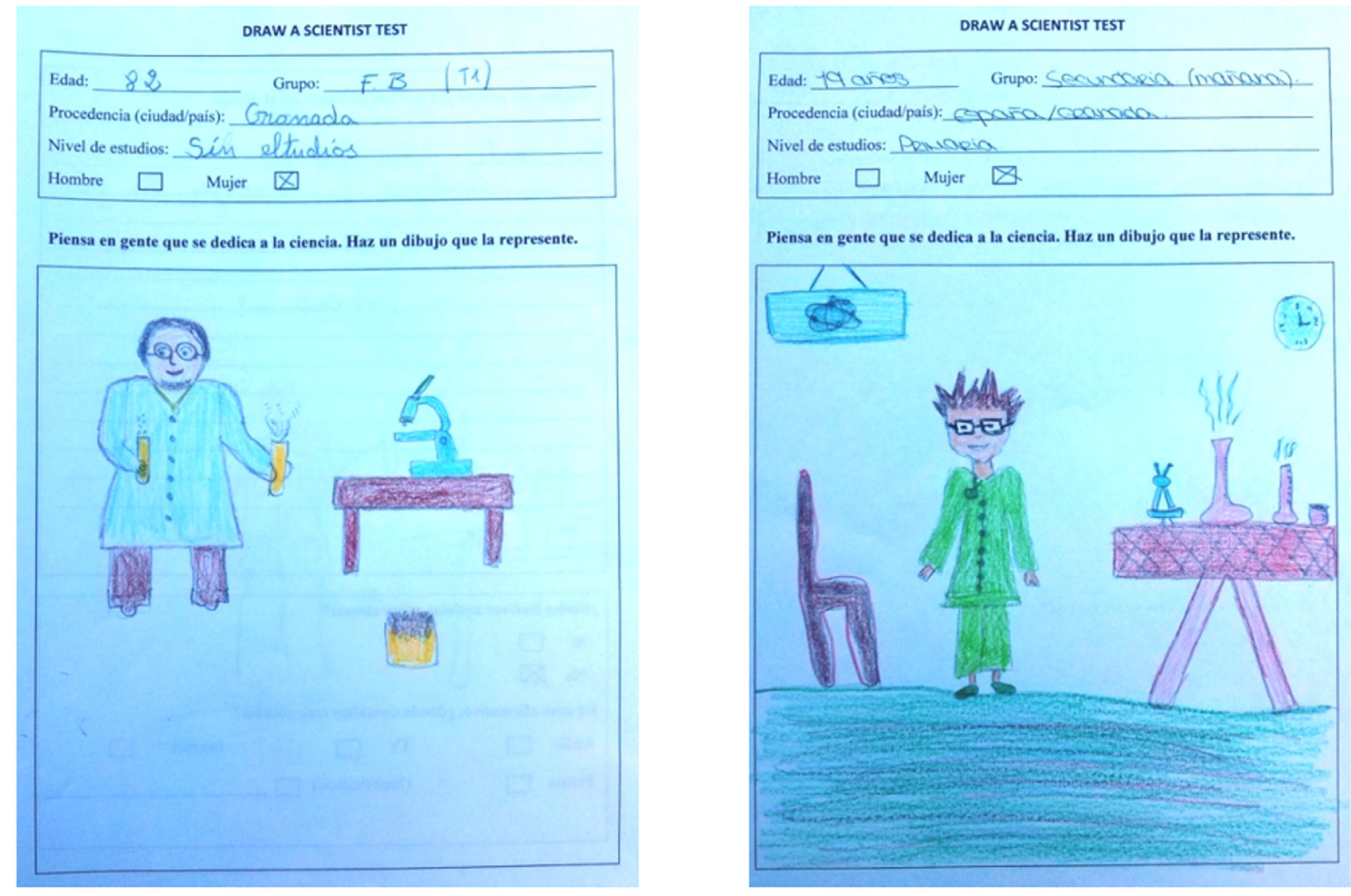

Figura 6. Dibujos realizados por alumnos de 82 años (izquierda) y 19 años (derecha).

Fuente: elaboración propia de los autores. 
número de estudiantes. Habría que preguntarse si la diferencia de razones que el alumnado dio en las fases y pretest y postest es debida a que algo ha cambiado en su concepción de la imagen del científico, o se debe simplemente a las imágenes presentadas en cada una de las fases. Por ello, sería aconsejable abrir una nueva línea de investigación utilizando las mismas imágenes de científicos en las fases pretest y postest, pero mucho más distanciadas en el tiempo.

Una propuesta de mejora para futuras investigaciones sería trabajar con un diseño comparativo, con grupo experimental y grupo control. Además, que contase con doble postest, distanciado en el tiempo, para comprobar si las concepciones regresan pasado un tiempo, tal y como ocurrió en el estudio realizado por Solano, Gil, Pérez y Suero, (2002) sobre la persistencia de preconcepciones sobre ciertos contenidos científicos, en este caso circuitos eléctricos, o el trabajo realizado por Vílchez y Ramos (2015) con contenidos del sistema Sol-Tierra-Luna.

Por otra parte, habría que investigar más a fondo cuál podría ser el origen de dicho arraigo ya que no parece que este tenga un origen relacionado con las características de edad, sexo, origen o estudios de las personas.

Por último, señalar que las futuras líneas de investigación deberían tener en cuenta la influencia de los medios de comunicación, pues se muestran como firmes candidatas a ser fuentes de percepciones distorsionadas de la actividad científica.

\section{Referencias}

Acevedo Díaz, J. A., Vázquez Alonso, Á., Manassero-Mas, M. A. y Acevedo-Romero, P. (2007). Consensos sobre la naturaleza de la ciencia: aspectos epistemológicos. Eureka, 4(2), 202-225. DOI: https://doi. org/10.25267/Rev Eureka ensen divulg cienc.2007.v4.i2.01

Acevedo Díaz, J. A. y García-Carmona, A. (2016). Rosalind Franklin y la estructura molecular del ADN: un caso de historia de la ciencia para aprender sobre la naturaleza de la ciencia. Revista Científica, 25, 162-175. DOI: https://doi.org/10.14483/udistrital.jour. RC.2016.25.a2

Barman, C. R. (1997). Students' views of scientists and science: Results from a national study. Science and Children, 35(1), 18.

Boylan, C. R., Hill, D. M., Wallace, A. R. y Wheeler, A. E. (1992). Beyond stereotypes. Science Education, 76, 465-476. DOI: https://doi. org/10.1002/sce.3730760502

Carrascosa Alís, J. (2013). Ideas alternativas en conceptos científicos. Revista Científica, 18, 112-137.

Chambers, D. W. (1983). Stereotypic images of the scientist: The Draw-a-Scientist Test. Science education, 67(2), 255-265. DOI: https://doi. org/10.1002/sce.3730670213

Fernández, I., Gil, D., Carrascosa, J., Cachapuz, A. y Praia, J. (2002). Visiones deformadas de la ciencia transmitidas por la enseñanza. Enseñanza de las Ciencias, 20(3), 477-488.

Finson, K. D. (2002). Drawing a Scientist: What We Do and Do Not Know After Fifty Years of Drawings. School science and mathematics, 102(7), 335-345. DOI: https://doi.org/10.1111/j.1949-8594.2002.tb18217.x

Kahle, J. (1989). Images of scientists: Gender issues in science classroom. Curtin University, Key Paper N. ${ }^{\circ}$ 1. Perth: Center for School Science and Mathematics. Recuperado de http://files. eric.ed.gov/fulltext/ED370785.pdf

Lederman, N. G. (2006). Research on nature of science: reflections on the past, anticipations of the future. Asia-Pacific Forum on Science Learning and Teaching, 7(1). Recuperado de http://www.ied.edu.hk/apfslt/

Mead, M. y Métraux, R. (1957). Image of the scientist among high-school students. Science, 126(3270), 384-390. DOI: https://doi. org/10.1126/science.126.3270.384

Organización para la Cooperación y el Desarrollo Económicos (OCDE) (2016). Pisa 2015 
Assessment and Analytical Framework: Science, Reading, Mathematic and Financial Literacy, París: OECD. DOI: https://doi. org/10.1787/9789264255425-en

Perales, F. J., Vílchez, J. M. y Sierra, J. L. (2004). Imagen y educación científica. Cultura y Educación, 16(3), 289-304. DOI: $\underline{10.1174 / 1135640042360960 .}$.

Ruiz-Mallén, I. y Escalas, M.T. (2012). Scientists seen by children: A case study in Catalonia, Spain. Science Communication, 34(4), 520-545. DOI: https://doi.org/10.1177/1075547011429199

Sanmartí, N. (2002). Didáctica de las ciencias en la educación secundaria obligatoria. Madrid: Síntesis.

Schibeci, R. A. (1986). Images of Science and Scientists and Science Education. Science Education, 70(2), 139-149. DOI: https://doi. org/10.1002/sce.3730700208

Sjøberg, S. (2000). Science and scientists: The SAS study. Acta Didáctica, 1. Recuperado de http:// www.uv.uio.no/ils/forskning/publikasjoner/ acta/acta-oslo/sciens-and-scientist.pdf
Solano, F., Gil, J., Pérez, A. L. y Suero, M. I. (2002). Persistencia de preconcepciones sobre los circuitos eléctricos de corriente continua. Revista Brasileira de Ensino de Física, 24(4), 460-470. DOI: https://doi.org/10.1590/ $\underline{\text { S1806-11172002000400013 }}$

Vázquez, A. y Manassero, M. A. (1998). Dibuja un científico: imagen de los científicos en estudiantes de secundaria. Infancia y Aprendizaje, 21(81), 3-26. DOI: https://doi. org/10.1174/021037098320825226

Vílchez González, J. M. y Perales-Palacios, F. J. (2006). Image of science in cartoons and its relationship with the image in comics. Physics Education, 41(3), 240-249.

Vílchez González, J. M. y Ramos Tamajón, C. M. (2015). La enseñanza-aprendizaje de fenómenos astronómicos cotidianos en la Educación Primaria española. Revista Eureka sobre Enseñanza y Divulgación de las Ciencias, 12(1), 2-21.

Whittle, C. (1997). Teaching Science by Television: The Audience, Education, History, and the Future. Base de datos ERIC (ED417079). 